RESEARCH REPORT

\title{
PREVALENCE OF ADOLESCENT IDIOPATHIC SCOLIOSIS AMONG PRIMARY AND SECONDARY GIRLS SCHOOLS OF SIKANDERABAD, KARACHI, PAKISTAN
}

\begin{abstract}
BACKGROUND AND OBJECTIVES

Scoliosis is the deviation in the lateral curvature of spine. This study aimed to estimate the prevalence of idiopathic scoliosis among the school going female population of Sikanderabad, Karachi, Pakistan between the ages of 11 to 20 years.
\end{abstract}

\section{STUDY DESIGN}

Cross-sectional study.

\section{STUDY SETTINGS AND PARTICIPANTS}

Study was conducted at Sikanderabad, Karachi, Pakistan. Adolescent female population of primary and secondary schools between the ages of 11-20 years were the targeted population.

\section{METHOD}

Data was collected by observation of the posture, palpation of spine and questionnaire. Examination was carried out by dividing the thoracic spine into three segments i-e; upper, middle and lower thoracic spine. Adam's forward bending test was used to assess the three segments of spine and the results were confirmed by using a scoliometer. Data was analyzed by using SPSS version 20.

\section{RESULTS}

The total sample consisted of 226 students. The mean age estimated was 13.61 with \pm 2.10 and the overall prevalance of idiopathic scoliosis was $21.16 \%$. Lower thoracic region was founded the most affected.

\section{CONCLUSION}

Study confirmed that scoliosis is prevalent in females especially in the lower thoracic region of spine and the mean age group affected is 13.61 years.

\section{KEYWORDS}

Adolescent Idiopathic Scoliosis, Cobb Angle, Spinal Deformity Screening, Scoliometer, Prevalence, Forward bending test

\author{
Sumaira Imran Forooqui \\ Associate Professor/Principal \\ Ziauddin College of Rehabilitation Sciences \\ Ziauddin University \\ sumairaimranfarooqui@gmail.com \\ Hakim Ullah \\ Senior Lecturer \\ Ziauddin College of Rehabilitation Sciences \\ Ziauddin University

\section{Munira Ali Mukadam} \\ DPT Student \\ Ziauddin College of Rehabilitation Sciences \\ muniraali_@hotmail.com

\section{Batool Zohra} \\ DPT Student \\ Ziauddin College of Rehabilitation Sciences \\ batoolzohrakarrar@gmail.com

\section{Isbah Sarfaraz} \\ DPT Student \\ Ziauddin College of Rehabilitation Sciences \\ Isbah.sarfaraz@yahoo.com

\section{Darakhshan Qamar} \\ DPT Student \\ Ziauddin College of Rehabilitation Sciences \\ drdarakhshanqamar@gmail.com

\section{Fatima Zahid} \\ DPT Student \\ Ziauddin College of Rehabilitation Sciences \\ fatima.zahid1@outlook.com
}

[Farooqui SI, Ullah H, Mukadam MA, Zohra B, Sarfaraz I, Qamar D, Zahid F. Prevalance of Adolescent Idiopathic Scoliosis among Primary and Secondary Girls schools of Sikanderabad, Karachi, Pakistan. Pak. j. rehabil. 2018:7(1);28-34] 


\section{INTRODUCTION}

Scoliosis is widespread present among school children with an estimated prevalence of $0.5 \%-3 \%$ worldwide'. Scoliosis is a lateral curvature of spine having Cobb's angle of $>10$. Its early diagnosis helps in early treatment that is bracing which avoids the need for surgery in future ${ }^{2}$. Scoliosis is categorized into two groups idiopathic and non-idiopathic. Non idiopathic has several types: Congenital: associated with genes, neuromuscular: it is due to inadequacy of stabilizers (muscles) of spine, infantile: 0-3yrs, juvenile: 4-10yrs, adolescent: 11-18yrs ${ }^{3}$. Many components can attribute to cause of scoliosis. Some of them are posture, genetics, obesity, and sedentary lifestyle, inappropriate school furniture, school bags or foot wears ${ }^{4}$. The classical age for screening in girls is before the onset menarche and likewise before the onset of puberty in boys i.e. 1-2 years later than girls 5 . The scapulothoracic complex is necessary for proper shoulder function. Patients with adolescent idiopathic scoliosis show altered scapula kinetics ${ }^{6}$.

According to a study $85 \%$ of females are affected from adolescent idiopathic scoliosis of age group between 9 and 18 years. Diagnosis is done by $x$ rays, physical examination and anamnesis being used.

The physical assessment involves shoulder and scapular evenness, ADAM's test, plumb line and triangle cut $^{3}$.

Research shows that Adam's test is commonly used for scoliosis screening'. In a research examination was done using angle of trunk rotation (ATR) as forward bending test (FBT) with help of scoliometer. ATR above 5 degree was believed to be positive and to rule out scoliosis greater than 10 degree Cobb's angle was used ${ }^{2}$. Modified Delphi approach is used for spinal deformity screening (SSSP's) in some countries around the world. The conceptual frame work of analysis used in this systemic review was approved by task force and thought to be conceptual to examine spinal deformity screening, which emphasis on five major elements/features. This model was used in other diagnostic program strongly. It also comprises of all WHO measures which are workable for evaluation strategies ${ }^{7}$.

Best diagnosis and assessment routine of postural examination is carried out in school. In this way spinal problems can be detected early. The tool for assessment used in this study includes an identification form, assessment of the flexibility of back muscle chain, group of socioeconomic characteristics, lifestyle, puberty, and ergonomic examination. Adam's forward bending test was also used to evaluate the suspected scoliosis ${ }^{4}$.

An overall compiled prevalence of idiopathic scoliosis in adolescents is $0.47 \%$ to $5.2 \%$ from differ- ent studies ${ }^{3}$. A school screening survey was performed in Surabaya Indonesia, study calculated about $2.93 \%$ of rate of prevalence in school age children between 9-16 years of age ${ }^{8}$. In the state of Sao Paulo Brazil a study measured the presence of unknown cause of scoliosis in adolescent 2,562 children between age 10 to 14 years participated and were assessed by ADAM's forward bending test and with a scoliometer measuring the trunk rotation angle, overall $1.5 \%$ prevalence rate was calculated?.

A cross sectional study in Singapore measured the prevalence of idiopathic scoliosis in school going children of four different age groups and to correlate the current statistics with previous 15 years study performed in 1982 to 1997. According to statistics collected from 35,558 boys and 37,141 girls the presence of adolescent idiopathic scoliosis was $1.37 \%$ for girls and $0.21 \%$ for boys at the age of $11-12$ years and the prevalence of $2.22 \%$ of girls and $0.66 \%$ of boys was estimated at the ages of 13 to 14 years. $40.1 \%$ of children had thoracolumbar curve changes. There was no significant increase founded in the result when compared with previous 1982 to 1997 researches ${ }^{10}$.

In southern region of Brazil, it was evaluated that the rate of prevalence of scoliosis in adolescent age group school student is $1.4 \%$ with no significant correlation of body over weight and excessive school material carried by school students'. A cross sectional study was obtained in primary school of Cankkale to determine the presence of idiopathic scoliosis in school going children. 12 schools were selected by cluster sampling method in which total 2604 students participated and underwent examination with scoliometer and postural screening. Students with greater degree measurement underwent radiographic examination in which out of 6 students 8 were diagnosed with adolescent idiopathic scoliosis. The study concluded that $1 \%$ to $2 \%$ of children up to age group of 15 affected with adolescent idiopathic scoliosis ${ }^{11}$.

The treatment of scoliosis can be altered according to its type and severity. In less severe cases exercises is the main treatment to be given ${ }^{12}$. The effectiveness of schroth scoliosis specific exercises was checked in a study in which one hour long training session was delivered along with 30 to 45 minutes of home program exercises. This trial proved that this exercise program can be used for the treatment of adolescent idiopathic scoliosis ${ }^{13}$.It was found that there is no special outcome of physiotherapy in people who are at risk of progression of scoliosis. However, bracing can be used as conservative management of idiopathic scoliosis in adolescents $^{14}$. Measuring the Cobb's angle is the most accurate method to assess the degree of scoliosis. The cobb's angle which shows less than 10 degree of deviation of spinal curve usually does not require 
a surgical treatment ${ }^{15}$. According to American academy of orthopedic surgeons the surgeons worldwide suggest a cobb angle greater than 45 degree as an indication to use surgical approach to correct the spinal curvature and prevent it from progression ${ }^{16}$. A retrospective study was obtained in Brazil which included 2 groups of patients with thoracolumbar anterior and posterior arthrodesis. 22 patients underwent surgery, group 1 comprising 11 patients who were with anterior arthrodesis and 11 patients of group 2 with posterior arthrodesis. Pre and post-operative $x$ rays were observed along with fusion and alignment, breakage of material was also assessed post operatively. Study concluded that group 1 had an average of 4.81 fused vertebra and group 2 had 6.36 fused vertebra. Group 2 had no complications while group 1 had broken implants ${ }^{17}$.

According to the worldwide analysis of scoliosis it is concluded that scoliosis is prevalent in adolescent females due to genetic, hormonal and different causes. Early assessment plays a great role in diagnosis and prevention from further progression of the disease. Less severe cases of scoliosis in which Cobb's angle is less than 400, physical therapy intervention coupled with spinal braces has a good role in correction of the spinal curve because these are usually due to postural muscles imbalance. Where's angle more than 400 need surgical approach. The aim of the study is to determine the prevalence of idiopathic scoliosis in adolescent's female population of primary and secondary schools in order to spread the awareness and stop its progression among the population of Sikanderabad, Karachi, Pakistan.

\section{METHODOLOGY}

\section{Study settings and population}

A study developed in the public \& private schools of Sikanderabad, Karachi, Pakistan which included school going females between the ages of 11 to 20 years.

\section{Study design \\ Cross sectional study.}

\section{Duration of study}

6 to 8 months.

\section{Sampling technique}

Simple random sampling

\section{Sample size}

sample size collected for the detection of adolescent idiopathic scoliosis was 226.

\section{Data analysis}

The obtained data is used for calculating the preva- lence by using SPSS version 20. Standard deviation and mean of the whole data was calculated on the parameters including age, upper thoracic spine, mid thoracic spine and lower thoracic spine.

\section{Inclusion criteria}

- Adolescent age between 11-20 years

- Female gender

\section{Exclusion criteria}

- Recent trauma

- Previous spinal fracture or surgery

- Leg length discrepancy

- Congenital scoliosis

\section{Data collection procedure}

The individual was asked to bend forward till the spine becomes equidistant to parallel plane with arms extended, patient was observed from front and was looked for a "rib hump", and individual with rib hump with scoliotic curves greater than 5 degrees was considered as positive. (Normally the thoracic curve is 1 to $4 \mathrm{~cm}$ with apex on C7.

\section{Data collection tool}

Data was collected by observation of the posture, palpation of spine curvatures and by using a self-administrated Questionnaire. Examination was carried out by using Adam's forward bending test and the results were confirmed by using a scoliometer which is a specific tool used for the examination of scoliosis.

\section{Assessment parameters}

Adams forward bending test and scoliometer readings of three segments of thoracic region. That includes:

- Upper thoracic segment

- Middle thoracic segment

- Lower thoracic segment

\section{Ethical considerations}

- Written permission was taken by an individual prior to participation in the study.

- Maintaining the dignity of the participant was a priority.

- All the personal data of the individual was kept confidential.

- Authenticity of an organization participating in the research was ensured.

\section{RESULTS}

The total sample of screening programme consisted of 226 school children. The screening was based on the criteria of adolescent age group and the gender focused was female. The mean age estimated was $13.61 \pm 2.10$ and the overall prevalance of adolescent idiopathic scoliosis calculated in Sikanderabad was $21.16 \%$. According to table-1 girls between the ages of 12-14 years have greatest 
prevalence of idiopathic scoliosis.

\begin{tabular}{|l|l|l|l|}
\hline \multicolumn{3}{|c|}{ AGE } \\
\hline & Frequency & Percent & $\begin{array}{l}\text { Valid } \\
6 \%\end{array}$ \\
\hline valid3.00 & 1 & 0.4 & 0.4 \\
10.00 & 2 & 0.9 & 0.9 \\
11.00 & 27 & 11.9 & 11.9 \\
12.00 & 48 & 21.2 & 21.2 \\
13.00 & 34 & 15.0 & 15.0 \\
14.00 & 47 & 20.8 & 20.8 \\
15.00 & 25 & 11.1 & 11.1 \\
16.00 & 19 & 8.4 & 8.4 \\
17.00 & 16 & 7.1 & 7.1 \\
18.00 & 3 & 1.3 & 1.3 \\
19.00 & 3 & 1.3 & 1.3 \\
20.00 & 1 & 0.4 & 0.4 \\
Total & 226 & 100.0 & 100.0 \\
\hline
\end{tabular}

TABLE-1 Shows percentage of age.

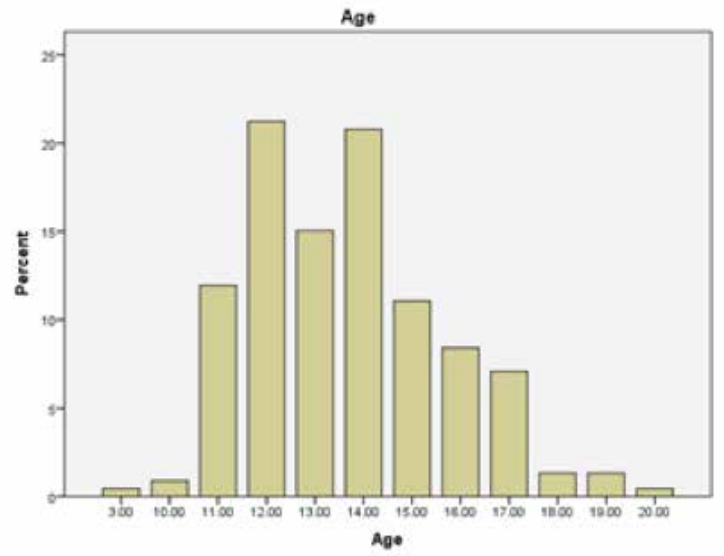

FIGURE-1 shows the percentage of age

The analysis was made by dividing the assessment into 3 segments of thorax. The mean of the upper thoracic curve was $2.18 \pm 2.31$.

Table-2 demonstrates that $>5$ degrees of scoliosis in upper thorax was found in $20.2 \%$ of girls and $42.9 \%$ had no scoliosis.

\section{SCOLIOSIS UT}

\begin{tabular}{|l|l|l|l|}
\hline & Frequency & Percent & Valid \% \\
\hline valid.0 & 97 & 42.9 & 42.9 \\
1.00 & 11 & 4.9 & 4.9 \\
2.00 & 12 & 5.3 & 5.3 \\
3.00 & 36 & 15.9 & 15.9 \\
4.00 & 24 & 10.6 & 10.6 \\
5.00 & 38 & 16.8 & 16.8 \\
6.00 & 3 & 1.3 & 1.3 \\
7.00 & 1 & 0.4 & 0.4 \\
8.00 & 1 & 0.4 & 0.4 \\
10.00 & 2 & 0.9 & 0.9 \\
12.00 & 1 & 0.4 & 0.4 \\
Total & 226 & 100.0 & 100.0 \\
\hline
\end{tabular}

TABLE-2 Shows the percentage of upper thoracic curve.

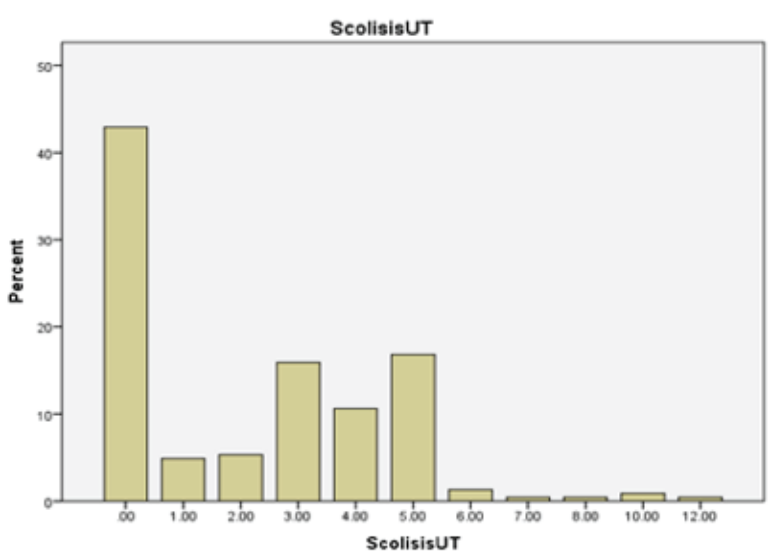

FIGURE-2 shows percentage of upper thoracic curve

Total mean of mid thoracic curve was $2.43 \pm 2.2$ out of which $20.7 \%$ girls had scoliotic curve greater than 5 degrees and $32.3 \%$ had normal curve (table-3).

SCOLIOSIS MT

\begin{tabular}{|l|l|l|l|}
\hline & frequency & percent & Valid\% \\
\hline Valid.00 & 73 & 32.3 & 32.3 \\
1.00 & 12 & 5.3 & 5.3 \\
2.00 & 28 & 12.4 & 12.4 \\
3.00 & 44 & 19.5 & 19.5 \\
4.00 & 22 & 9.7 & 9.7 \\
5.00 & 40 & 17.7 & 17.7 \\
6.00 & 1 & 0.4 & 0.4 \\
7.00 & 1 & 0.4 & 0.4 \\
8.00 & 5 & 2.2 & 2.2 \\
Total & 226 & 100 & 100 \\
\hline
\end{tabular}

TABLE-3 shows percentage of mid thoracic curve.

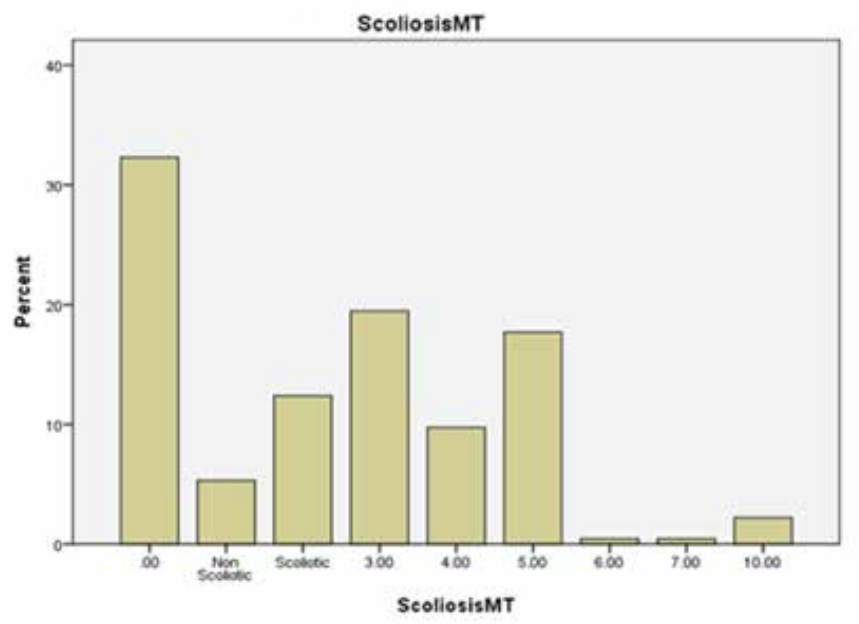

FIGURE-3 shows percentage of mid thoracic curve

Table-4 illustrates that the mean of the lower segment of thorax was $2.54 \pm 2.32$. $22.6 \%$ students were positive for scoliosis and $31.4 \%$ were screened as non scoliotic. 
SCOLIOSIS LT

\begin{tabular}{|l|l|l|l|}
\hline & frequency & percent & Valid \% \\
\hline Valid.00 & 71 & 31.4 & 31.4 \\
1.00 & 17 & 7.5 & 38.9 \\
2.00 & 22 & 9.7 & 48.7 \\
3.00 & 40 & 17.7 & 66.4 \\
4.00 & 24 & 10.6 & 77.0 \\
5.00 & 37 & 16.4 & 93.4 \\
6.00 & 6 & 2.7 & 96.0 \\
7.00 & 2 & 0.9 & 96.9 \\
8.00 & 3 & 1.3 & 98.2 \\
9.00 & 4 & 1.8 & 100.0 \\
Total & 226 & 100 & \\
\hline
\end{tabular}

TABLE-4 shows percentage of lower thoracic curve.

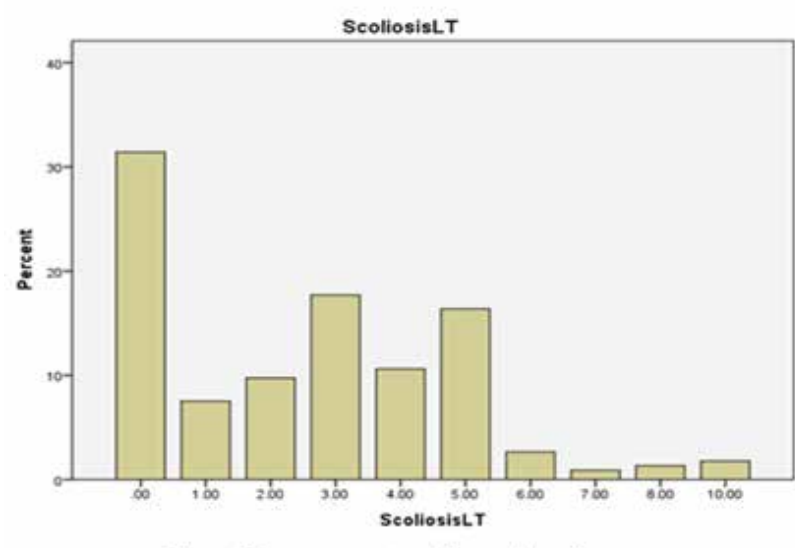

Figure-4 Shows percentage of lower thoracic curve

It is concluded that lower thoracic region is mostly affected with idiopathic scoliosis in adolescent population, the average age of 13 years is most prone to develop scoliosis and the safest age is 20 years of adolescents.

\section{DISCUSSION}

This study was based on a school screening survey program of adolescent idiopathic scoliosis. The highlighted population was adolescent girls of primary and secondary schools of sikanderabad, Karachi, Pakistan. 226 was the total population who participated in our study excluding those who missed the assessment program. the inclusion criteria for students in our study was female gender, age between 11 and 20 years, school going population and the exclusion criteria was visible structural deformity, previous spinal surgical history and age greater than 20 years. A study was conducted in 2015 which found out that best diagnosis and assessment routine of postural examination is carried out in school. In this way spinal problems can be early detected and the risk factors associated with it. The tool for assessment used in this study includes an identification form (name, age, and gender), scoliosis assessment, assessment of the flexibility of back muscle, socio-economic characteristics, anthropometric measurements, lifestyle, puberty, ergonomic examination. Adam Forward Bent Test also used to evaluate the suspected scoliosis ${ }^{4}$. Comparing this study with a study done in Singapore which found adolescent girls had higher prevalence of $1.0 \%$ in 11 to 12 years girls and $3.12 \%$ in girls of age group between 16 to 17 years and the lowest prevalence was found between 6 to 7 years of age which is $0.12 \%^{18}$. Whereas our study found highest prevalence in 12 years of age which is 21.2 $\%$ and lowest in 20 years which is $0.4 \%$ as shown in table-1. According to a study conducted in Sao Paulo Brazil this gender difference in scoliosis is due to early inset of puberty than males so both genders should be screened in age 10 to 14 years for early detection of scoliosis'. Adam's forward bending test was the main assessment tool and scoliometer was used for confirming the degree of scoliosis. The students who scored $>5$ degrees were considered as scoliotic and those having degrees $<5$ were considered as non scoliotic. This was similar to a study held in southern Brazil which consisted of positioning the students in forward leaning position and checking their right and left rib humps, test known as Adam's forward bending test ${ }^{1}$. Another study conducted in the year 2017 which proved the effectiveness of Adam's forward bending in his school screening program by first assessing all the students with Adam's forward bending test and those with positive results were further examined with scoliometer to check their angle of trunk rotation ${ }^{2}$.In a survey Walter Reed Visual Assessment Scale (WRVAS) and Trunk Appearance Perception Scale (TAPS) were used. Individuals with idiopathic scoliosis and no previous surgical history were enrolled. TAPS and SRS-22 questionnaire was done by every individual and the complete spinal $X$ ray was received ${ }^{19}$.The degree of upper thoracolumbar/lumber structural curves were documented. A literature review concluded that adolescent idiopathic scoliosis has high incidence of back pain. This review estimates 0.4 to $5.2 \%$ prevalence of adolescent idiopathic scoliosis. Prevalence of this condition is unequal shoulders, waist, rib cage and unequal breast in females. For examination Adam's forward bending test is declared the best test ${ }^{20}$.

Our examination was carried out by dividing the thoracic spine into three segments i-e upper thoracic spine, middle thoracic spine and lower thoracic spine. The purpose of dividing the thoracic spine into these three regions was the suspicion of finding scoliosis in thoracic region in adolescent school going population due to carrying heavy school bags on shoulders which can alter their posture and disturb the mechanics of spine. Our investigation about upper thoracic spine out of 226 students resulted in 46 students positive for idiopathic scoliosis and 83 were non scoliotic. 38 students had 5 degrees of scoliosis, 3 students with 6 degrees of scoliosis, 2 with 10 degrees while 3 students having 
7.8 and 12 degrees of scoliosis. Hence, severe scoliosis was rare to find in the upper thoracic spine (table-2). As described in table-3 in the middle thoracic spine 40 students had 5 degrees of scoliosis, 5 students had 10 degrees of scoliosis and 2 had 6 and 7 degrees of scoliosis. A total of mid thoracic scoliosis estimated was in 47 students out of 226 and 106 had no scoliosis. Table-4 shows the results of lower thoracic spine in which a total of 52 students were diagnosed with having scoliosis, 37 had 5 degrees of scoliosis, 6 had 6 degrees of scoliosis, 2 had 7 degrees, 3 had 8 degrees and 4 had 10 degrees of idiopathic scoliosis. Students having no scoliosis were 103 out of 226. The total calculation shows that mid thoracic spine had highest degrees of scoliosis and is more prone to develop idiopathic scoliosis in adolescent population ${ }^{21}$. Another study by Cowell et al was reviewed which was based on concept of idiopathic scoliosis related to gene mutation. He studied 110 families with scoliosis. Author found $33 \%$ families affected as compared to the controlled group which was the general population $^{22}$. According to the study that exercise and physical therapy proves to be efficient in minimizing the development of idiopathic scoliosis. Improving the quality of life in children affected by adolescent idiopathic scoliosis with the help of various guidelines rather than surgical procedures has proven to be advantageous ${ }^{23}$. According to a meta-analysis and systemic review lower back pain prevalence is high due to scoliosis. Treatment for back pain is done by conservative management using different techniques however effects of treatment are not added. Surgical treatment showed more elevation in pain. Bracing did not elevate the pain in patients wearing brace and those without brace. Screening is a procedure for identification of undiagnosed diseases by application of different test and measures for any specific disease or defect ${ }^{24}$. Another study was conducted to find out the surgical outcomes of correction in young adult's thoracic idiopathic scoliosis, the adults aged between 10 to 18 years. The study concluded that the surgical correction of scoliotic curve done in early adulthood has more advantages and there are chances of increased health risks if the surgical intervention is done in late adulthood ${ }^{25}$.

\section{CONCLUSION}

Study concluded that the total prevalence of idiopathic scoliosis in adolescent female school going population of Sikanderabad was $21.16 \%$ in the mean age of 13.61 years. It is found that scoliosis is prevalent in the lower thoracic region of spine in this population. In this survey students who were diagnosed with scoliosis were taught different rehabilitation strategies for correction of posture, low back pain relief to prevent further progression of the disease.

\section{REFRENCES}

[1] Nery LS, Halpern R, Nery PC, Nehme KP, Tetelbom Stein A. Prevalence of scoliosis among school students in a town in southern Brazil. Sao Paulo Med J. 2010;128(2):69-73

[2] Deepak AS, Ong JY, Choon DS, Lee CK, Chiu CK, Chan CY, Kwan MK. The Clinical Effectiveness of School Screening Programme for Idiopathic Scoliosis in Malaysia. Malays Orthop J. 2017;1 1(1):41.

[3] Konieczny MR, Senyurt H, Krauspe R. Epidemiology of adolescent idiopathic scoliosis. J Child Orthop. 2012;7(1):3-9.

[4] Baroni MP, Sanchis GJ, De Assis SJ, Dos Santos RG, Pereira SA, Sousa KG, Lopes JM. Factors associated with scoliosis in schoolchildren: a cross-sectional population-based study. J. Epidemiol. 2015;25(3):212-20.

[5] Adobor RD, Rimeslatten S, Steen H, Brox Jl. School screening and point prevalence of adolescent idiopathic scoliosis in 4000 Norwegian children aged 12 years. Scoliosis. $2011 ; 6(1): 23$

[6] Misterska E, Głowacki J, Okręł A, Laurentowska M, Głowacki M. Back and neck pain and function in females with adolescent idiopathic scoliosis: A follow-up at least 23 years after conservative treatment with a Milwaukee brace. PloS one. 2017;12(12):e0189358.

[7] Labelle H, Richards SB, De Kleuver M, Grivas TB, Luk KD, Wong HK, Thometz J, Beauséjour $M$, Turgeon I, Fong DY. Screening for adolescent idiopathic scoliosis: an information statement by the scoliosis research society international task force. Scoliosis. 2013;8(1):17.

[8] Komang-Agung IS, Dwi-Purnomo SB, Susilowati A. Prevalence Rate of Adolescent Idiopathic Scoliosis: Results of School-based Screening in Surabaya, Indonesia. Malays Orthop J. 2017;11(3):17.

[9] Penha PJ, Ramos NL, Andrade RM, Schmitt AC, João SM. Prevalence of Adolescent Idiopathic Scoliosis in the State of São Paulo, Brazil. Spine. 2018;43(24):1710-8

[10] Yong F, Wong HK, Chow KY. Prevalence of adolescent idiopathic scoliosis among female school children in Singapore. Ann. Acad. Med. Singap. 2009;38(12):1056.

[11] Yilmaz H, Zateri C, Vurur S, Bakar C. Prevalence of adolescent idiopathic scoliosis among primary school children in Canakkale, Turkey. Scoliosis. 2012;7(1):037.

[12] Romano M, Minozzi S, Bettany-Saltikov J, Zaina F Chockalingam N, Kotwicki T et al. Exercises for adolescent idiopathic scoliosis. Cochrane Database Syst Rev. 2012;(8).

[13] Schreiber S, Parent EC, Moez EK, Hedden DM, Hill D, Moreau MJ, Lou E, Watkins EM, Southon SC. The effect of Schroth exercises added to the standard of care on the quality of life and 
muscle endurance in adolescents with idiopathic scoliosis-an assessor and statistician blinded randomized controlled trial: "SOSORT 2015 Award Winner". Scoliosis. 2015;10(1):24.

[14] Weiss HR. Physical therapy intervention studies on idiopathic scoliosis-review with the focus on inclusion criteria 1. Scoliosis. 2012;7(1):4.

[15] Westrick ER, Ward WT. Adolescent idiopathic scoliosis: 5-year to 20-year evidence-based surgical results. J Pediatr Orthop B. 2011;31:S61-8.

[16] Horne JP, Flannery R, Usman S. Adolescent idiopathic scoliosis: diagnosis and management. Am Fam Physician. 2014;89(3):193-8.

[17] Queruz JC, Kato A, Aguiar CA, Avila LM, Rocha LE. Evaluation of idiopathic scoliosis by anterior and posterior arthrodesis. Coluna/Columna. 2015;14(2):88-92.

[18] Daruwalla JS, Balasubramaniam P, Chay SO, Rajan U, Lee HP. Idiopathic scoliosis. Prevalence and ethnic distribution in Singapore school children. J Bone Joint Surg Br. 1985;67(2):182-184.

[19] Bago J, Sanchez-Raya J, Perez-Grueso FJ, Climent JM. The Trunk Appearance Perception Scale (TAPS): a new tool to evaluate subjective impression of trunk deformity in patients with idiopathic scoliosis. Scoliosis. 2010;5(1):6.

[20] Choudhry MN, Ahmad Z, Verma R. Adolescent Idiopathic Scoliosis. Open Orthop J. 2016;10: 143-54. doi:10.2174/1874325001610010143

[21] Wajchenberg $M$, Astur N, Kanas M, Martins DE. Adolescent idiopathic scoliosis: current concepts on neurological and muscular etiologies. Scoliosis Spinal Disord. 2016;11(1):4.

[22] Cowell HR, Hall JN, MacEven GD. Genetic aspects of idiopathic scoliosis: a Nicholas Andry Award essay, 1970. Clin Orthop Relat Res. 1972;86:121-31.

[23] Baba MR, Shenoy RM, Soman A. Current concepts of SEAS (Scientific Exercise Approach to Scoliosis): Adolescent Idiopathic scoliosis (AIS). Int J Cur Res Rev. 2017;9(4):33.

[24] Balagué F, Pellisé F. Adolescent idiopathic scoliosis and back pain. Scoliosis Spinal Disord. 2016;11(1):27.

[25] Zhu F, Bao H, Yan P, Liu S, Zhu Z, Liu Z, Bao M, Qiu Y. Comparison of Surgical Outcome of Adolescent Idiopathic Scoliosis and Young Adult Idiopathic Scoliosis. Spine. 2017;42(19):E1 133-9. 